\title{
The Src homology-2 protein Shb modulates focal adhesion kinase signaling in a $B C R-A B L$ myeloproliferative disorder causing accelerated progression of disease
}

\author{
Karin Gustafsson¹, Maria Jamalpour ${ }^{1}$, Camilla Trinh¹, Michael G Kharas² and Michael Welsh ${ }^{1 *}$
}

\begin{abstract}
Background: The Src homology-2 domain protein B (Shb) is an adapter protein operating downstream of several tyrosine kinase receptors and consequently Shb regulates various cellular responses. Absence of Shb was recently shown to reduce hematopoietic stem cell proliferation through activation of focal adhesion kinase (FAK) and thus we sought to investigate Shb's role in the progression of leukemia.

Methods: Wild type and Shb knockout bone marrow cells were transformed with a retroviral BCR-ABL construct and subsequently transplanted to wild type or Shb knockout recipients. Disease latency, bone marrow and peripheral blood cell characteristics, cytokine expression, signaling characteristics and colony formation were determined by flow cytometry, qPCR, western blotting and methylcellulose colony forming assays.

Results: It was observed that Shb knockout BCR-ABL-transformed bone marrow cells produced a disease with death occurring at earlier time points compared with corresponding wild type controls due to elevated proliferation of transformed bone marrow cells. Moreover, significantly elevated interleukin- 6 and granulocyte colony-stimulation factor mRNA levels were observed in Shb knockout c-Kit + leukemic bone marrow cells providing a plausible explanation for the concurrent peripheral blood neutrophilia. Shb knockout leukemic bone marrow cells also showed increased ability to form colonies in methylcellulose devoid of cytokines that was dependent on the concomitantly observed increased activity of FAK. Transplanting BCR-ABL-transformed Shb knockout bone marrow cells to Shb knockout recipients revealed decreased disease latency without neutrophilia, thus implicating the importance of niche-derived cues for the increase of blood granulocytes.

Conclusions: Absence of Shb accelerates disease progression by exerting dual roles in BCR-ABL-induced leukemia: increased cell expansion due to elevated FAK activity and neutrophilia in peripheral blood, the latter dependent on the genetic background of the leukemic niche.
\end{abstract}

Keywords: $B C R-A B L$, Focal adhesion kinase, Shb, Chronic myeloid leukemia, Neutrophilia

\footnotetext{
* Correspondence: Michael.welsh@mcb.uu.se

'Department of Medical Cell Biology, Uppsala University, Husargatan 3,

75123 Uppsala, Sweden

Full list of author information is available at the end of the article
} 


\section{Background}

Hematopoiesis is a life-long process supported by a finely tuned network of proto-oncogenes and tumor suppressor genes controlling the self-renewal and proliferation of hematopoietic stem and progenitor cells (HSCs and HPCs). Deregulation of any of these elements has the potential to give rise to neoplasms [1]. Leukemic cells thus show characteristics of upregulated signaling cascades promoting self-renewal, increased cell cycle entry as well as prevention of apoptosis [2,3].

Chronic myeloid leukemia (CML) is myeloproliferative malignancy induced by the translocation between chromosomes 9 and 22 leading to the fusion of the $c-A B L$ gene with the break point cluster region (BCR) gene [4]. The resulting oncogene $B C R-A B L$ is a constitutively active tyrosine kinase with the ability to affect a broad range of signaling pathways including Ras, phosphatidylinositol-3 kinase (PI-3 K), and Rac [5-8]. Hence, cells expressing $B C R-A B L$ display increased proliferative ability combined with reduced apoptotic rates and abnormal migratory characteristics [9-12]. $B C R-A B L$ may, in addition, cause other types of leukemia.

Intracellular signaling events are not the only factors contributing to the progression of the disease. A common feature of most types of tumors is their ability to change the microenvironment to promote neoplastic growth. The tumor cells can either secrete tumor -promoting factors or the surrounding stroma can be induced to generate conditions favorable for expansion of leukemic cells $[13,14]$. CML bone marrow secretes increased levels of interleukin -6 (IL -6) and granulocyte colony -stimulating factor (G CSF), both established as cytokines that stimulate myeloid expansion and differentiation [10,11,15-17]. Additionally, in leukemia, the stromal compartment has a reduced ability to support normal hematopoiesis, thus further enhancing the growth advantage of the leukemic cells $[10,11,18,19]$.

The adaptor protein Shb is one of four members in a family of adaptor proteins with homologous tyrosine phosphorylation sites and Src homology 2 (SH2) domains [20-23]. Shb has been shown to operate downstream of tyrosine kinase receptors exerting versatile effects on a number of signaling pathways [24]. The $\mathrm{SH} 2$ domain of Shb binds to phosphotyrosines on activated receptors such as the platelet derived growth factor receptor (PDGFR), the IL-2 receptor and the T cell receptor (TCR) [24]. Shb's various signaling domains further recruit intracellular signaling mediators, including focal adhesion kinase (FAK), Src, phosphatidylinositol 3-kinase (PI3K), Vav-1, and c-Abl [24,25], thereby regulating cytoskeletal rearrangements, proliferation as well as apoptosis [24].

Shb's influence on the hematopoietic system has been documented in a number of studies. Shb knockout embryonic stem cells display reduced colony formation and delayed expression of hematopoietic markers [26]. CD4+ $\mathrm{T}_{\mathrm{H}}$ cells isolated from a $S h b$ knockout mouse exhibit a $\mathrm{T}_{\mathrm{H}} 2$ biased cytokine profile upon in vitro stimulation [27]. In HSCs, the loss of Shb results in hyperactivation of FAK leading to impaired HSC proliferation and failure to uphold long -term maintenance of the myeloid compartment [28]. The reduction of HSC proliferation prompted us to investigate Shb's role in a stem cell mediated myeloproliferative model. $B C R-A B L$-induced myeloid disease is one of the most established systems to study factors that are known to be coordinated downstream of tyrosine kinase signaling. We observe that $S h b$-deficiency results in a more rapid progression of disease.

\section{Results}

\section{Loss of Shb results in BCR-ABL-driven leukemogenesis} with shorter latency

A recent study suggested that $S h b$ knockout HSCs are less proliferative and fail to maintain the myeloid compartment over time [28] and consequently, we decided to investigate the effect of $S h b$ deletion on the development of myeloid neoplasia. Shb knockout and wild type bone marrow cells were transformed with $B C R-A B L-$ GFP encoding retrovirus and subsequently transplanted to wild type recipients. As the mice were monitored for disease progression $S h b$ knockout recipients displayed symptoms and became moribund at earlier time points than their wild type counterparts (Figure 1a). In addition, when comparing the average life-span of wild type and Shb knockout transplanted mice in each individual experiment (a separate event of parallel wild type and Shb knockout bone marrow transfection followed by transplantation to recipient mice of which mean survivals were determined in each group) it was observed that absence of Shb shortened survival by $2.7 \pm 0.4$ days $(\mathrm{n}=5, \mathrm{p}<0.01)$. Upon gross pathological examination there were no differences between mice receiving wild type or Shb knockout leukemic bone marrow at the time of death. Weight loss is one of the more prominent symptoms at the end stage of the disease; Shb null mice started losing weight earlier but the end stage weight did not significantly differ between the two groups (Figure 1b). The number of cells was also found to be equal in wild type and $S h b$ knockout bone marrows (Figure 1c) and flow cytometric analysis of myeloid lineage markers Gr-1 and Mac-1 failed to demonstrate any differences between wild type and $S h b$ deficient bone marrows in either GFP + $(B C R-A B L-G F P)$ or total myeloid cell numbers (Figure $1 \mathrm{~d}$ and e) [29]. As the leukemia progresses, immature hematopoietic cells will be driven out of the bone marrow and extramedullary hematopoiesis will occur at alternative sites such as spleen and liver. The result is considerable splenomegaly and hepatomegaly. In addition, leukemic cells collect in the lungs causing pulmonary hemorrhage [30]. End stage spleen and liver weights were, however, found 

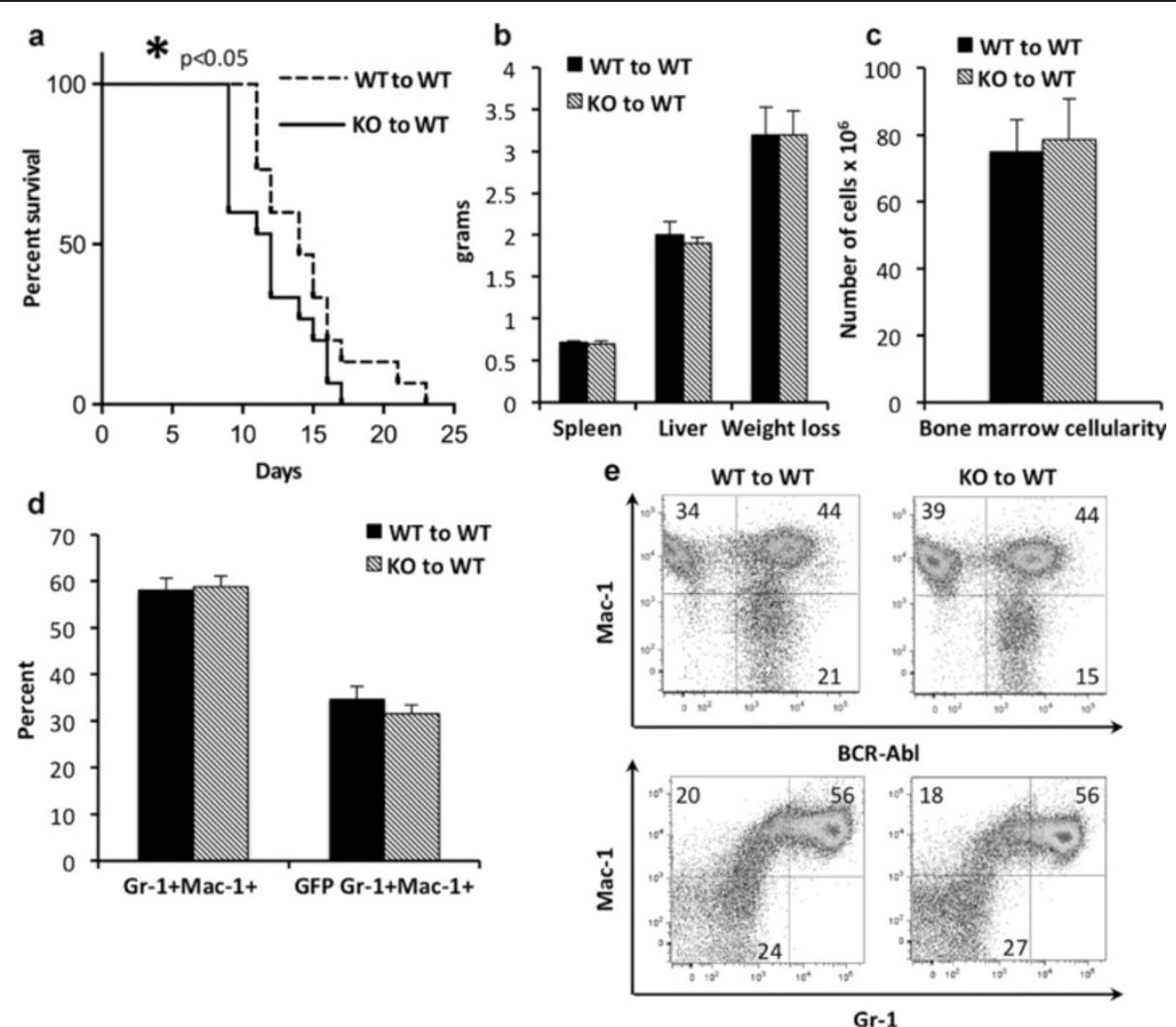

Figure 1 Effects of Shb deletion on disease progression in murine model of CML. (a) Kaplan-Meier curve demonstrating survival of mice receiving either wild type or Shb knockout BCR-ABL transformed bone marrow from 5-FU treated mice. (b) Analysis of various disease parameters including liver and spleen weight as well as weight loss at the end-stage of the disease. (c) Bone marrow cell numbers from the tibia, femur and the iliac bones were determined at the time of death. (d and e) Bone marrow cells were stained with fluorescently labeled antibodies directed against Gr-1 and Mac-1 and subsequently analyzed with FACS for GFP (BCR-ABL), Mac-1 and GR-1. Plots are representative of a typical experiment. Data are presented as mean \pm SEM and based on 15 mice of each genotype from 5 independent experiments (retroviral transformation and transplantation occurring at 5 separate occasions). *denotes $p<0.05$ as determined by Student's t-test.

to be similar for mice transplanted with wild type and Shb knockout bone marrows (Figure 1b) and hematoxylin-eosine stained sections of spleens, livers and lungs also did not reveal any differences with regards to leukemic cell infiltration (Additional file 1: Figure S1). The percentage GFP + myeloid cell number was decreased slightly in Shb knockout spleen whereas the non-leukemic myeloid cell percentage was unchanged (Additional file 1: Figure S1). Analysis of May Grünwald-Giemsa stained peripheral blood smears did on the other hand reveal significantly increased numbers of leukocytes (Figure 2a and c) in the absence of Shb. Normally, more aggressive forms of myeloid leukemia are distinguished by elevated levels of immature, blast cells in peripheral blood [30]. Shb deficiency did, however, confer increased proportions of cells with a mature neutrophil morphology and reduced relative numbers of blasts (Figure $2 \mathrm{~b}$ and $\mathrm{c}$ ). Although the relative proportion of blast cells was lower in the Shb knockout, absolute numbers of blast cells were not different $\left(105 \pm 11 \times 10^{6}\right.$ cells per $\mathrm{ml}$ in the wild type and $126 \pm 22 \times 10^{6}$ cells per $\mathrm{ml}$ in the Shb knockout).
More mature stages of myeloid cells are defined as Gr- $1^{\mathrm{Hi}} \mathrm{Mac}-1^{\mathrm{Hi}}$ [29]. However Gr-1 and Mac-1 expression in peripheral blood did not differ significantly between wild type and $S h b$ knockout samples (Figure 2d and e). Although the histological findings in peripheral blood could not be corroborated by changes in expression levels of lineage defining markers through FACS analysis, it is plausible that, as these cells are neoplastic, cell surface marker expression does not faithfully reflect morphological maturity. Notably, when the $\mathrm{Gr}-1^{\mathrm{Hi}} \mathrm{Mac}-1^{\mathrm{Hi}}$ population was examined for expression of $B C R-A B L$, determined by FACS analysis of $\mathrm{GFP}^{+}$cells, recipients of $S h b$ null transformed bone marrow displayed a decreased percentage of $B C R-A B L^{+}$myeloid cells in peripheral blood. Shb deficient samples showed an almost 1:1 ratio of $B C R-A B L^{+}$to $B C R-A B L^{-}$cells whereas wild type recipients had a ratio of $1.8: 1$ (Figure $2 \mathrm{~d}$ and $\mathrm{f}$ ). Since the total blood cell count was higher in the Shb knockout (Figure 2a), the absolute numbers of $B C R-A B L^{+}$myeloid cells did, however, not differ between wild type and knockout, suggesting that the non-malignant 

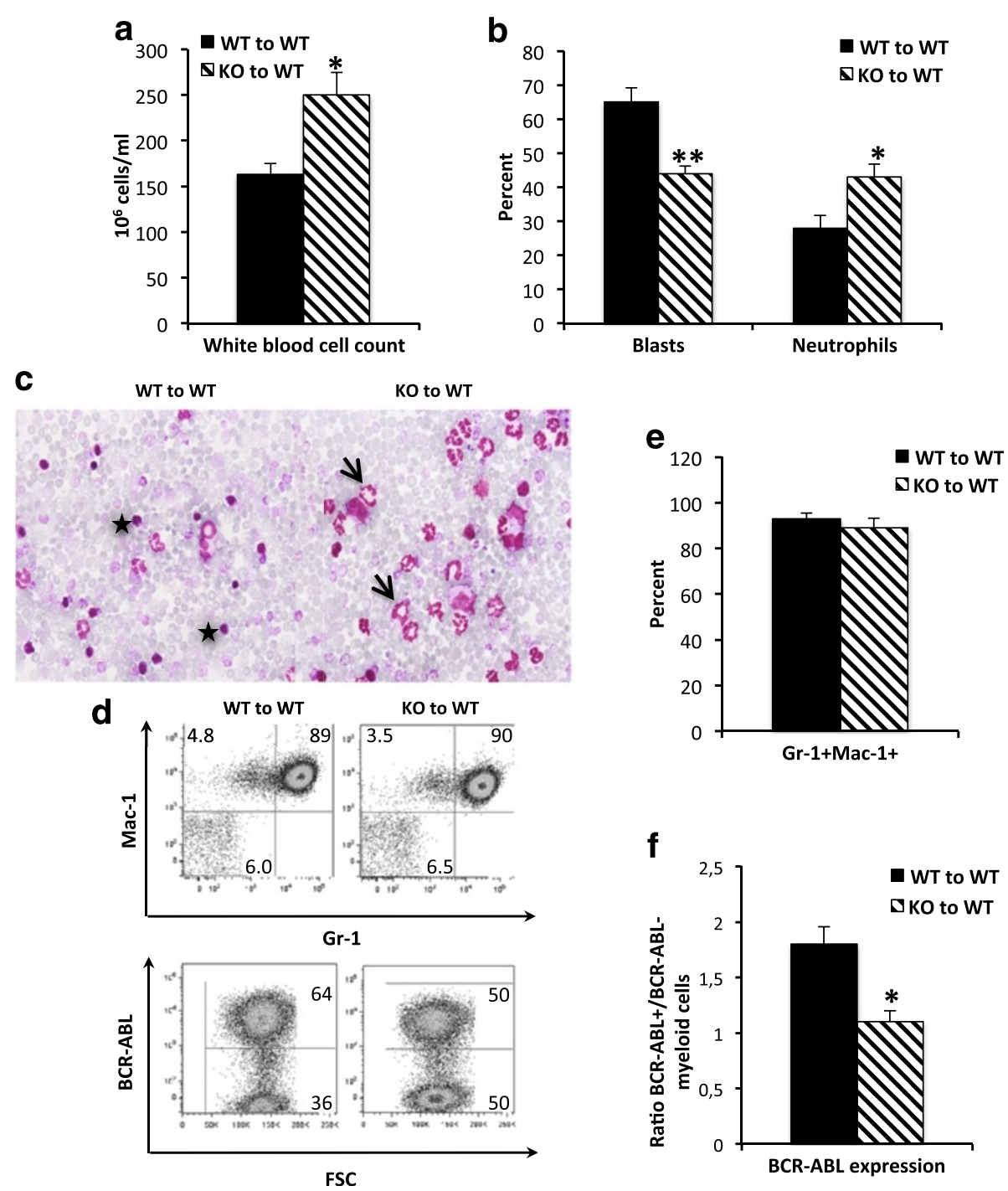

Figure 2 Evaluation of peripheral blood profile in leukemic wild type and Shb knockout mice. Peripheral blood smears were stained with May Grünwald-Giemsa; (a and $\mathbf{c}$ ) the white blood cell count was established by differential counts and ( $\mathbf{b}$ and $\mathbf{c}$ ) the proportions of morphologically mature and immature cells were determined [stars point to blast cells and arrow to mature neutrophils]. (d and e) FACS analysis of Gr-1 and Mac-1 expression in peripheral blood. (d and f) The ratio of $B C R-A B L^{+}$and $B C R-A B L^{-}$within the myeloid compartment was determined by evaluation of GFP expression using FACS analysis. The plots are representative of a typical experiment. The results are presented as mean values \pm SEM from 9 mice of each genotype in 3 independent experiments. ${ }^{*}$ and * represents $p<0.01$ and $p<0.05$ respectively as determined by Student's $t$-test.

pool of myeloid cells had selectively expanded in the absence of Shb (Additional file 2: Figure S2).

In summary, the loss of Shb expression in malignant hematopoiesis exhibits a disease with shorter latency. Simultaneously, elevated numbers of mature neutrophil granulocytes are observed in peripheral blood.

\section{Shb deletion confers a proliferative advantage and} reduces apoptosis in $B C R-A B L^{+}$lineage-negative cells In order to further examine how the loss of $S h b$ expression accelerates $B C R-A B L$-induced leukemia, the proliferation status of hematopoietic stem and progenitor cells was determined at the time of death. Most of the bone marrow's stem and progenitor potential is found within the $\mathrm{Lin}^{-} \mathrm{C}-\mathrm{Kit}^{+}$population of cells. Flow cytometric analysis of the proliferation marker Ki-67 within the $B C R-A B L^{+}$ $\mathrm{Lin}^{-} \mathrm{c}-\mathrm{Kit}^{+}$population revealed a 1.9 -fold increase in the proliferation rate (Figure 3a upper panel and Figure 3b) in Shb knockout bone marrow. Moreover, the more differentiated $\mathrm{Lin}^{+} \mathrm{c}-\mathrm{Kit}^{+}$population was also found to exhibit an elevated cell cycle rate in Shb null bone marrow (Figure 3a middle panel and Figure 3c). Absence of Shb did not affect the sizes of the $\mathrm{Lin}^{-} \mathrm{C}-\mathrm{Kit}^{+} \mathrm{CD} 150^{+} \mathrm{CD} 48^{-}$, the 

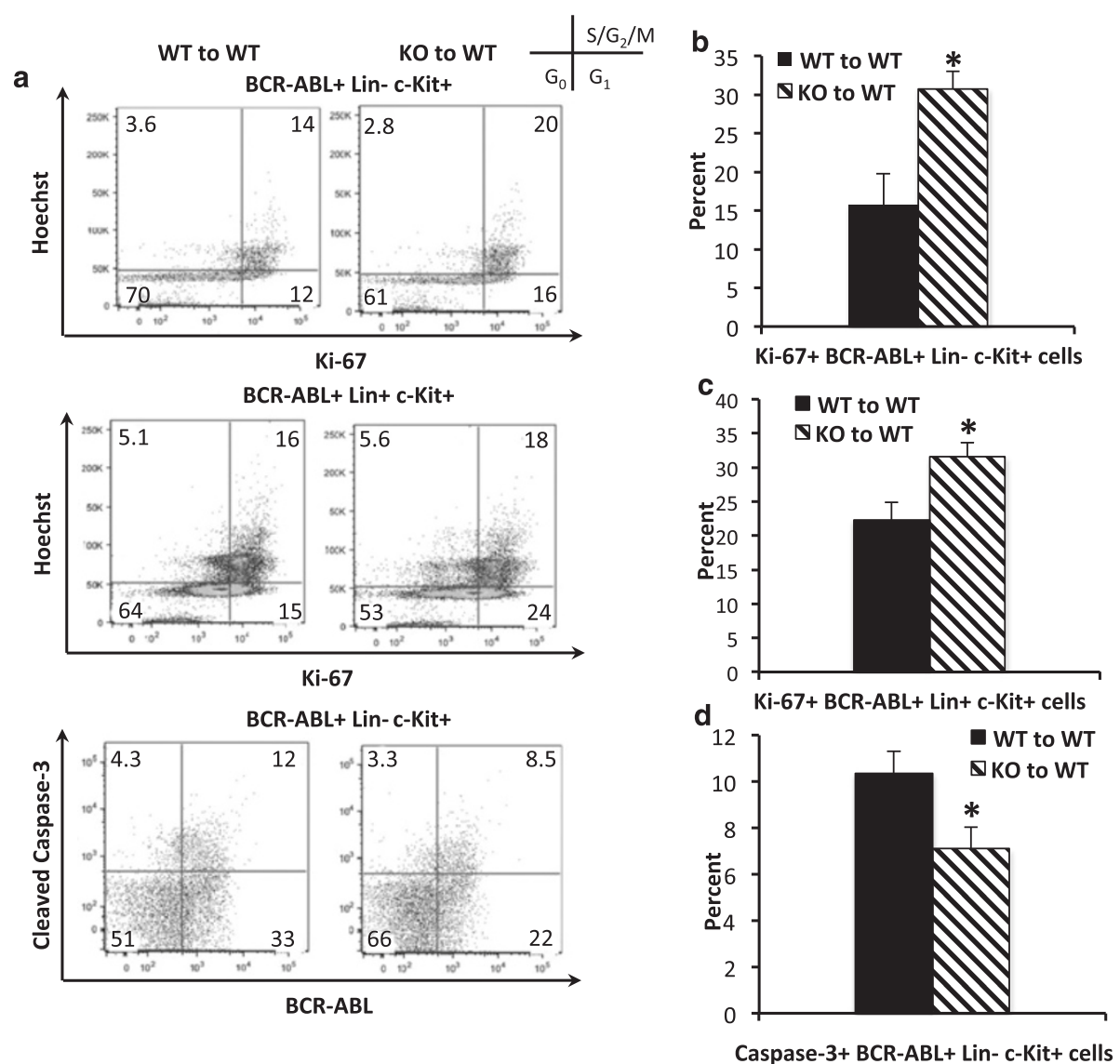

Figure 3 Proliferation and apoptosis in $\mathrm{BCR}-\mathrm{ABL}^{+}$hematopoietic progenitors assessed by flow cytometric analysis of $\mathrm{Ki}-67$ and cleaved Caspase-3. ( $\mathbf{a}, \mathbf{b}$ and $\mathbf{c})$ The cell cycle status in $B C R-A B L^{+} \operatorname{Lin}^{-} \mathrm{c}-\mathrm{Kit}{ }^{+}$and $B C R-A B L^{+} \mathrm{Lin}^{+}$bone marrow was examined by staining for proliferation marker Ki-67 in combination with the DNA binding dye Hoechst 33342. FACS plots are representative of an average experiment. (a and d) The staining for presence of cleaved Caspase-3 was used to determine the percentage of apoptotic cells within the $B C R-A B L^{+} L_{i n}{ }^{-} C-K_{i t}{ }^{+}$population. FACS plots are representative of a typical experiment. Data are presented as mean values \pm SEM with 9 mice from each genotype from 3 independent experiments. ${ }^{*}$ denotes $p<0.05$ as determined by Student's $t$-test.

$\mathrm{Lin}^{+} \mathrm{C}-\mathrm{Kit}^{+}$, and the $\mathrm{Lin}^{-} \mathrm{C}-\mathrm{Kit}^{+}$populations (Additional file 3: Figure S3a, b and c).

A hallmark of $B C R-A B L$ transformed bone marrow cells is their resistance to apoptosis [9]. To determine if the apoptotic rate was also altered in the absence of $\mathrm{Shb}, B C R-A B L^{+} \mathrm{Lin}^{-} \mathrm{C}-\mathrm{Kit}^{+}$bone marrow cells were stained for cleaved caspase- 3 when the mice became moribund. A modest, but significant decrease in the percentage of cleaved caspase $-3^{+}$ cells indicates that $B C R-A B L^{+} \mathrm{Lin}^{-} \mathrm{c}-\mathrm{Kit}^{+}$cells are less apoptotic as a result of $\operatorname{Sh} b$ deletion (Figure 3a lower panel and Figure 3d). There was no effect on apoptosis in the $\mathrm{Lin}^{+} \mathrm{C}-\mathrm{Kit}^{+}$population (data not shown). In conclusion, the data imply that ablation of $S h b$ expression is associated with an increased expansion of the leukemic lineage-negative progenitor cell population through enhancement of proliferation and survival.
Shb knockout leukemic bone marrow is hypersensitive to cytokine stimulation and expresses increased levels of G-CSF and IL-6

Normal bone marrow only forms hematopoietic colonies in the presence of the appropriate cytokines; malignantly transformed stem and progenitor cells however, are capable of growth factor independent proliferation and differentiation [31]. To assess the response to cytokine stimulation, cells from leukemic wild type and Shb knockout bone marrows were seeded into semisolid media containing a cytokine cocktail with the potential to support myeloid as well as erythroid differentiation. Both wild type and Shb null bone marrow readily formed colonies with no significant difference in the number or the types of colonies formed (Figure 4a). When plating the cells on a gradient of granulocytemonocyte colony-stimulating factor (GM-CSF), noticeable differences were observed as compared to the experiments 


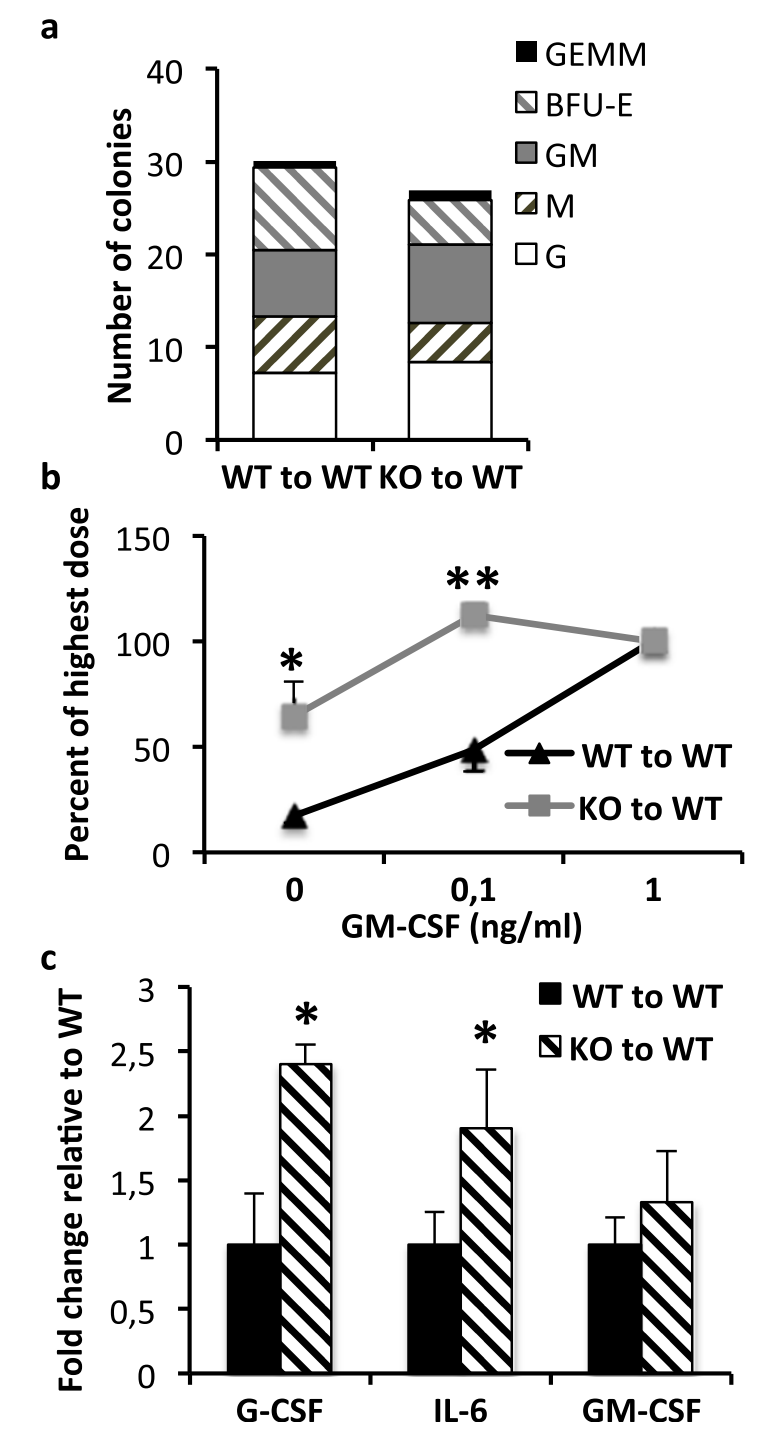

Figure 4 Effects of Shb deficiency on hematopoietic colony formation ability and cytokine expression in BCR-ABLtransformed bone marrow. (a) Bone marrow cells were plated on M3434 semisolid medium containing cytokines supportive of myeloid and erythroid colony growth. The number and types of colonies were determined on day 10 of culture [Granulocyte Erythroid Monocyte Megakaryocyte (GEMM), Burst-forming Unit Erythroid (BFU-E), Granulocyte Monocyte (GM), Monocyte (M),

Granulocyte (G)]. Data are means based on 3 mice of each genotype. (b) A gradient of $0,0.1$ and $1 \mathrm{ng} / \mathrm{ml}$ of GM-CSF was used to evaluate cytokine responsiveness in leukemic bone marrow cells. Results are presented as percentage of the highest GM-CSF dose. Means \pm SEM are representative of 3 mice of each genotype. (c) The expression levels of various hematopoietic cytokines were determined by semi-quantitative real-time RT-PCR in samples isolated from c-Kit ${ }^{+}$ leukemic bone marrow. All $C_{t}$ values were normalized to $\beta$-actin and Shb knockout samples were related to corresponding wild type values. Means are presented as $2_{t}^{-\Delta C} \pm$ SEM to demonstrate fold change in mRNA content. Data are based on 6 mice of each

genotype from 2 independent experiments for $\mathrm{c}^{-\mathrm{Kit}^{+}}$cells and 3 mice of each genotype from 1 experiment for unfractioned bone marrow. *denotes $p<0.05$ respectively as determined by Student's $t$-test. in which the cells were plated in methylcellulose supplemented with multiple cytokines. It was revealed that Shb deficient bone marrow had an increased potential to support cytokine-independent growth and responded at lower concentrations of GM-CSF. In the absence of cytokines Shb knockout bone marrow formed 3 times as many colonies as the wild type (Figure $4 \mathrm{~b}$ ) and at a concentration of $0.1 \mathrm{ng} / \mathrm{ml} \mathrm{GM-CSF}$ the knockout produced twice as many colonies.

To further explore the cytokine signaling networks in our model, the expression levels of a number of cytokines, known to regulate $B C R-A B L$-induced leukemogenesis and hematopoietic cell proliferation and differentiation, were determined. In order to facilitate a distinction between cytokine production within the bone marrow as a whole and the hematopoietic compartment, bone marrow was first fractionated based on c-Kit expression, as most HSCs and HPCs are $\mathrm{c}-\mathrm{Kit}^{+}$. Transcription of GM-CSF was unchanged in both the c-Kit ${ }^{+}$compartment and in unfractionated bone marrow (Figure $4 \mathrm{c}$ and Additional file 4: Figure S4). The expression of G-CSF and IL-6 was on the other hand significantly elevated in c-Kit ${ }^{+}$cells (Figure 4c) but not in total bone marrow (Additional file 4: Figure S4), suggesting that the increased cytokine production is limited to the hematopoietic compartment. This is in line with previous reports suggesting that leukemic progenitors secrete IL- 6 and G-CSF in an autocrine fashion $[10,32]$. Other factors, such as TNF $\alpha, \mathrm{IL}-1 \alpha$, IL-1 $\beta$, IL-4, MIP-1 $\alpha$, MIP-1 $\beta$, SCF, IL-3, thrombopoietin and angiopoietin-2, have also been demonstrated to be important factors in promoting the proliferation of leukemic HSCs and HPCs [10,18]. The transcript levels of these factors were therefore determined in c-Kit enriched and unfractionated bone marrow, but no differences were detected between wild type and Shb deficient samples (Additional file 4: Figure S4).

Additionally, G-CSF has been linked to impaired bone marrow retention of leukemic HSCs due to decreased production of the chemokine CXCL12 by bone marrow stromal cells [10]. There was however no detectable difference in CXCL12 expression in total (unfractionated) bone marrow (relative expression of CXCL12 was $1 \pm 0.15$ in wild type and $0.73 \pm 0.25$ in Shb knockout). Reduced expression of CXCL12 in bone marrow has been shown to increase the number of HSCs found in the spleen [10]. Flow cytometric analysis of splenic HSCs revealed no difference between wild type and Shb knockout recipients (data not shown), further supporting the notion that the elevated levels of G-CSF do not appear to affect the invasion of Shb deficient leukemic HSCs to the spleen.

These results thereby indicate that $S h b$ serves as a modulator of cytokine expression levels thus possibly explaining the increased numbers of neutrophils in 
blood from $B C R-A B L$ transformed Shb deficient bone marrow.

\section{Accelerated BCR-ABL-induced leukemia in Shb knockout} recipient mice as a consequence of Shb deficiency

We decided to investigate the progression of disease when $B C R-A B L$-transformed wild type and Shb knockout bone marrow cells were transplanted to $S h b$ knockout recipient mice instead. The myeloproliferative leukemia was also accelerated in this setting when compared to wild type control (Figure 5a). Transplantation of $B C R-A B L$-transfected bone marrow to wild type and knockout recipients in a parallel experiment revealed no consistent difference in latency (results not shown). Unlike the situation with wild type recipients (see Figure $2 b$ and c), no signs of neutrophilia were observed (Figure 5b and c) when Shb knockout bone marrow was transplanted to knockout recipients. Colony formation in methylcellulose supplemented with cytokines was similar regardless of bone marrow cell genotype (Figure 5d). The expression of GCSF and IL- 6 in c-Kit ${ }^{+}$bone marrow cells was unaltered by $S h b$ deficiency (Figure 5e), explaining the absence of peripheral blood neutrophilia. This contrasted to what was seen with wild type recipients, suggesting that the host genotype in combination with the genotype of the transformed donor cells is critical for this response. The most likely explanation is interplay between transformed bone marrow cells and leukemic niche cells. Consequently, increased production of GCSF and IL-6 in BCR-ABL Shb knockout bone marrow cells required a wild type niche.

\section{Enhanced FAK and STAT3 activity of Shb deficient leukemic ${\mathrm{c}-\mathrm{Kit}^{+}}^{+}$bone marrow cells}

An increase in basal signaling activity in response to ablated $S h b$ expression has been noted in several types of tissue $[27,28]$. The activities of pathways controlling proliferation and survival were therefore analyzed in unstimulated c-Kit ${ }^{+}$bone marrow cells. As noted in nonmalignant HSCs [28], FAK activity was also increased in leukemic Shb knockout c-Kit ${ }^{+}$bone marrow (Figure 6a) transplanted to wild type mice. Myeloid leukemias are often characterized by hyperphosphorylation of STAT3 and STAT5 [33]. STAT5 phosphorylation was similar in Shb knockout and wild type samples (Additional file 5: Figure S5), whereas STAT3 activity was significantly increased in the knockout (Figure 6b). Notably, both
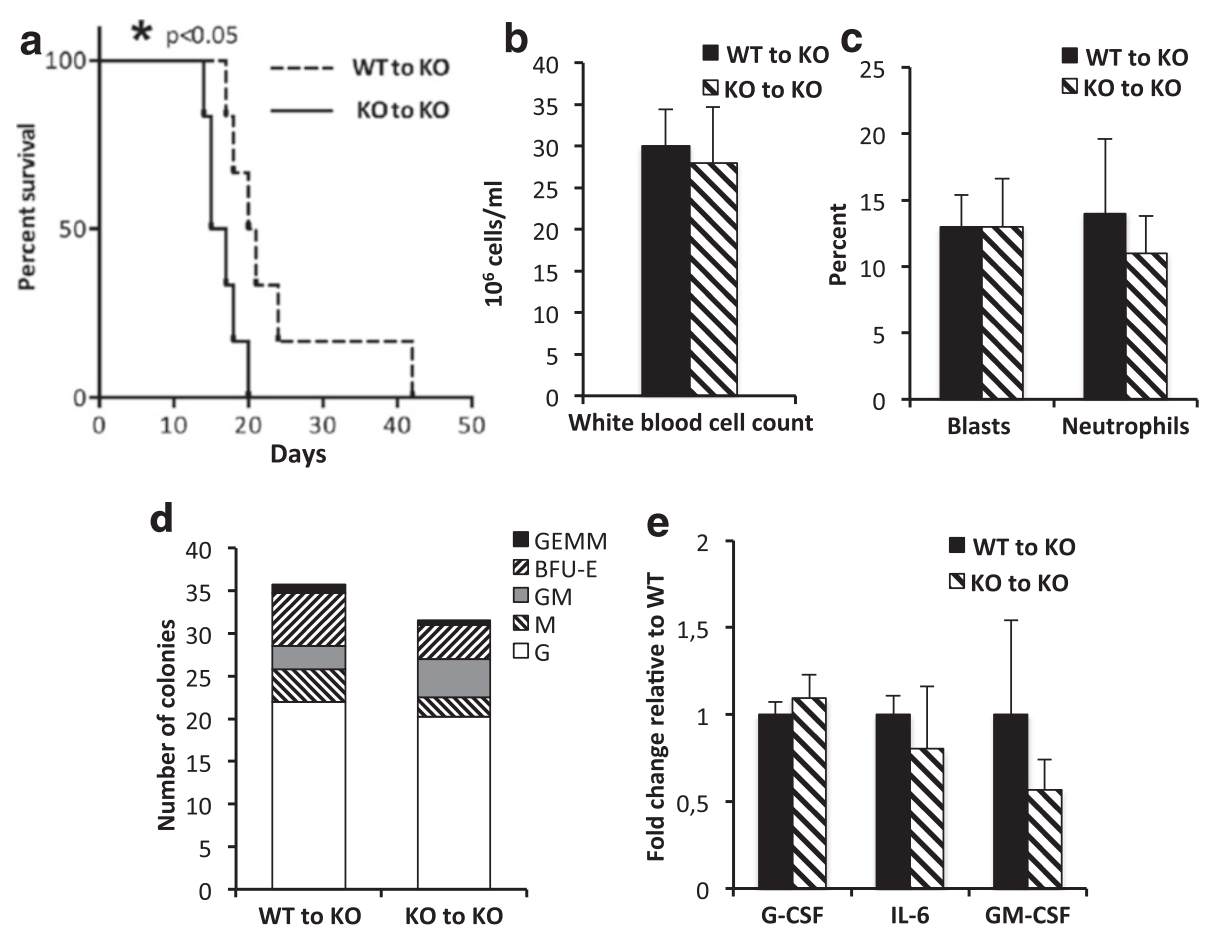

Figure 5 Effects of Shb deletion on disease progression of BCR-ABL-transformed bone marrow cells transplanted to Shb knockout recipient mice. (a) Kaplan-Meier curve demonstrating survival of Shb knockout mice receiving either wild type or Shb knockout BCR-ABL-transformed bone marrow. (b) White blood cell counts in peripheral blood at the time of death. (c) Relative numbers of mature neutrophils and blasts in peripheral blood at the time of death. (d) Colony formation assay of c-Kit enriched bone marrow cells grown in cytokine-supplemented methylcellulose. (e) Cytokine mRNA levels in c-kit-enriched bone marrow cells. 

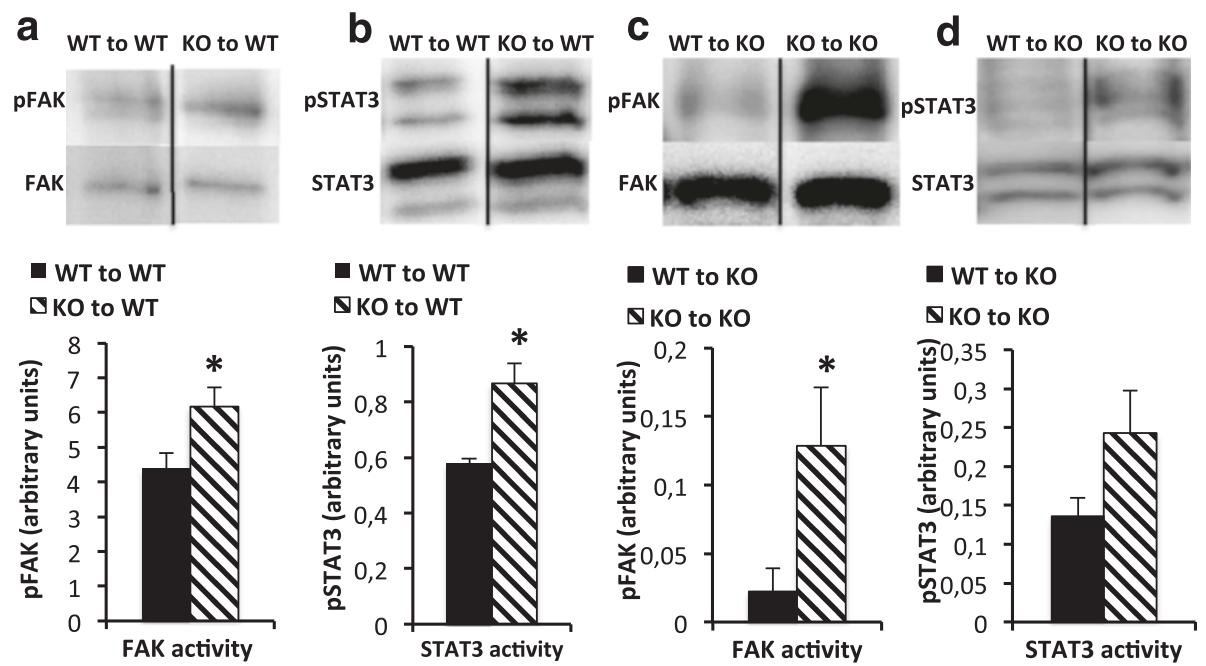

Figure 6 Activity of FAK $(\mathbf{a}, \mathbf{c})$ and STAT3 $(\mathbf{b}, \mathbf{d})$ in $\mathbf{c}-\mathrm{Kit}^{+}$bone marrow cells from leukemic mice. The phosphorylation status of FAK and STAT3 was determined by Western blot analysis. ( $\mathbf{a}$ and $\mathbf{b})$ show bone marrow cells from wild-type recipients, (c and d) show bone marrow cells from Shb knockout recipients. Activation was evaluated by immunoblotting for phospho- and total FAK and STAT3 respectively. Protein phosphorylation was related to total protein content on the same blot and signal strength was estimated by densitometric analysis. Means are presented in arbitrary units \pm SEM and are based on 6 mice of each genotype in 2 independent experiments. * denotes $p<0.05$ respectively as determined by Student's $t$-test.

G-CSF and IL-6 signal via STAT3 activation [34,35]. When FAK and STAT3 activities were monitored in leukemic $\mathrm{Shb}$ deficient c-Kit ${ }^{+}$bone marrow isolated from $S h b$ knockout recipient mice, increased activity of FAK was detected (Figure 6c) whereas STAT3 activity was not consistently elevated (Figure 6d). Consequently, FAK activation is a consistent feature of $B C R-A B L$-transformed Shb knockout bone marrow cells. STAT3 activity, on the other hand reflects the local cytokine milieu, which in turn depends on the interactions between the niche and the transformed bone marrow cells.

\section{Elevated FAK activity is important for the proliferative ability of BCR-ABL-transformed Shb knockout bone mar- row cells}

To address the relevance of the elevated FAK activity, c$\mathrm{Kit}^{+}$leukemic bone marrow cells were isolated and cultured in methylcellulose without cytokine addition (i.e. absence of GM-CSF) in the absence (control) or presence of FAK inhibitor 14. Shb knockout bone marrow cell colony formation was increased compared with corresponding wild type controls regardless of whether the cells were isolated from wild type or Shb knockout recipient mice (Figure $7 \mathrm{a}$ and c). The FAK inhibitor caused a statistically significant reduction in the numbers of colonies formed by the $S h b$ knockout bone marrow cells (Figure 7a and c). Dividing the number of colonies without FAK inhibitor treatment by that with FAK inhibitor treatment in the wild type situation yielded a ratio as high or even higher than the corresponding knockout situation, suggesting the possibility that there is indeed an effect of the FAK inhibitor on wild type leukemic bone marrow colony formation as well. However, the total number of colonies was too small relative the errors to obtain a statistical significant difference. We also determined the inhibitor-induced reduction in colony formation after FAK inhibition (Figure $7 \mathrm{~b}$ and $\mathrm{d}$ ) to illustrate the effect in the Shb knockout situation. This was significantly larger than that observed in wild type bone marrow cells (Figure $7 \mathrm{~b}$ and d) suggesting a preferentially greater importance of FAK signaling for proliferation in transformed Shb knockout bone marrow cells. Assuming that the total number of colonies formed reflects the proliferative status of the bone marrows at the time of death, the data thus support the view that elevated FAK activity as a consequence of Shb deficiency causes increased cell expansion accelerating the progression of disease. It is also possible that FAK plays a role for wild type leukemic cell colony formation as well.

\section{Discussion}

The adaptor protein Shb has been implicated in intracellular signaling events regulating proliferation, apoptosis and differentiation in a number of different cell types. Recently, HSC exhibited less proliferative activity in Shb knockout mice due to alterations in FAK signaling [28]. The present study aimed at relating those observations to conditions of neoplastic hematopoiesis. The results suggest that $S h b$ depletion accelerates $B C R$ - $A B L$-driven progression of myeloid neoplasia by causing decreased latency and increased numbers of myeloid cells in peripheral blood due to elevated FAK activity. In addition, nichedependent cues have an impact on disease progression with a bearing on cytokine production in bone marrow cells and neutrophilia in peripheral blood. 

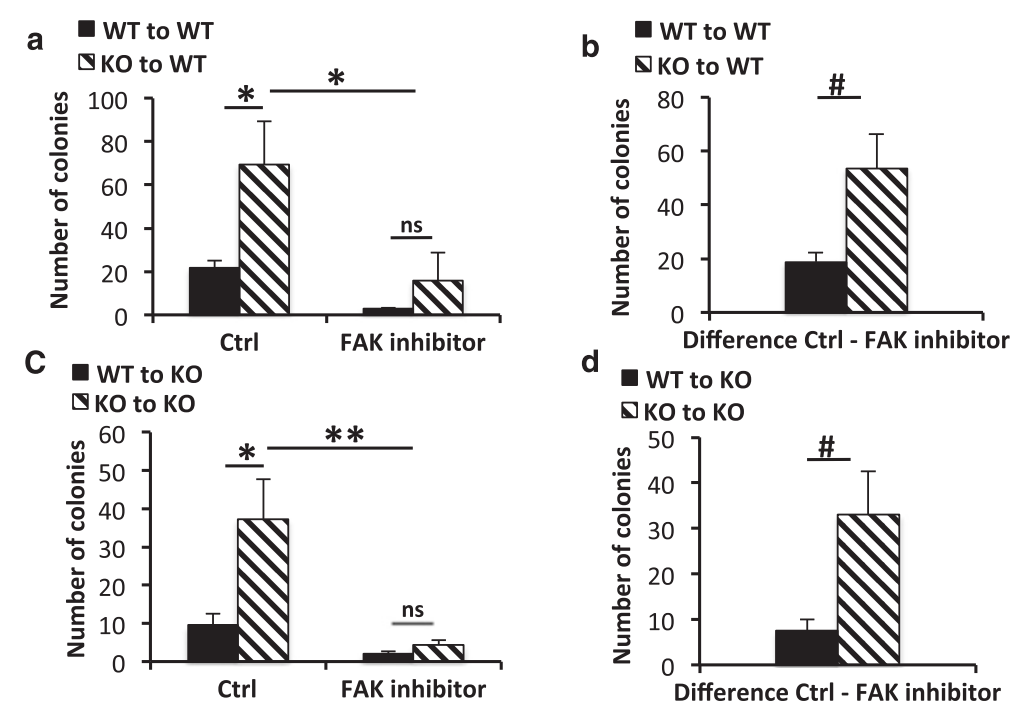

Figure 7 Effect of FAK inhibition on colony formation of wild-type and Shb knockout BCR-ABL-transformed bone marrow cells. c-Kit-enriched bone marrow cell $\left(10^{4}\right)$ were plated in methylcellulose in the absence of cytokines in the absence or presence of $10 \mu \mathrm{M}$ FAK inhibitor 14 and cultured for 5 days after which colony numbers were determined. (a) Colony formation of bone marrow cells isolated from wild-type recipients. (b) Inhibition of colony formation by inhibitor on bone marrow cells isolated from wild-type recipients. (c) Colony formation of bone marrow cells isolated from Shb knockout recipients. (d) Inhibition of colony formation by inhibitor on bone marrow cells isolated from Shb knockout recipients. The values in (b) and (d) were obtained by subtracting the inhibitor values from the corresponding control values. Means \pm SEM for 6 dishes (three mice) each group are given. * and ** indicate $p<0.05$ and 0.01 , respectively with one way ANOVA (Bonferroni). \# indicates $p<0.05$ when compared with wild-type using a Students' $t$-test. Ns $=$ not statistically significant.

FAK activity was recently noted to be significantly increased in normal HSCs in Shb deficient mice [28]. A similar increase in FAK activity was observed in $B C R$ $A B L$-transformed $S h b$ knockout c-Kit ${ }^{+}$bone marrow. Our current knowledge of FAK's effects on leukemogenesis is limited although the bulk of data suggest that active FAK promotes leukemogenesis. $B C R-A B L$ appears to induce FAK phosphorylation and siRNA silencing of FAK reduces survival of AML leukemia cell lines [36,37]. Additionally, observations from murine models and AML patients suggest that FAK may influence leukemia progression [38,39]. FAK is mainly activated by integrins, thus mediating signals between cells and their respective surroundings. Leukemic cells enhance their own growth by altering the bone marrow microenvironment $[10,11,18]$. FAK signaling could provide a key link between leukemic cells and the stromal cells of the hematopoietic niche. FAK expressing AML cells have been demonstrated to enhance the ability of bone marrow stroma to support leukemic growth through direct contact [40]. Moreover, in a recent study utilizing a murine model of $B C R-A B L$-induced leukemia, it was shown that soluble factors synergize with an unidentified contact-dependent mechanism to drastically change the hematopoietic niche composition to promote neoplastic progression [18]. The present colony formation experiments adding a FAK inhibitor in the absence of cytokines lend strong support to the notion that the increased tumor burden of transformed $S h b$ knockout bone marrow cells is mainly due to elevated FAK activity. In $S h b$ deficient $B C R-A B L$-transformed bone marrow, immature inn $^{-} \mathrm{c}-\mathrm{Kit}^{+}$HSCs and HPCs as well as more differentiated $\mathrm{Lin}^{+} \mathrm{c}-\mathrm{Kit}^{+}$cells, were found to proliferate at an increased rate and this finding is likely to reflect the same mechanism as the colony formation assay.

The $S h b$ deficient myelodysplastic neoplasia phenotype is also intriguing as the rapid progression of disease is associated with a pronounced neutrophilia when studied in wild type recipient mice. In most cases, more aggressive forms of leukemia are distinguished by a blood profile dominated by immature blasts [30]. Shb deficient c-Kit ${ }^{+}$ leukemic bone marrow cells were on the other hand found to express increased levels of granulopoietic factors IL-6 and G-CSF in these experiments. Myeloid differentiation is supported by IL- 6 through cell cycle regulation of myeloid progenitors and IL-6 also blocks lymphoid lineage commitment thus further enhancing myeloid expansion $[16,41,42]$. Moreover, leukemia progression is significantly hampered in $I L-6$ knockout mice directly linking this cytokine to disease [11]. This may involve effects on both malignant and non-malignant cells [11]. Peripheral blood from recipients transplanted with transformed $S h b$ knockout cells contained elevated numbers of $B C R-A B L^{-}$myeloid cells indicative of an expansion of non-malignant cells, possibly a result of the increased IL-6 expression. Neutrophil differentiation under homeostatic and stress conditions depends on G-CSF providing survival and 
differentiation signals to granulocytic progenitors [15,17]. Further demonstrating G-CSF's effect on neutrophil expansion is the finding that chronic neutrophilic leukemia, a rare myeloproliferative disorder characterized by excessive expansion of the neutrophilic population in blood and bone marrow, is linked to activating mutations in the CSF3R gene, the human receptor for G-CSF [43].

STAT3 phosphorylation was significantly augmented in c-Kit ${ }^{+}$bone marrow cells isolated from $\mathrm{Shb}$ knockout recipients on wild type background. Notably, G-CSF and IL-6 signaling pathways converge in the activation of the transcription factor STAT3 and STAT3 is the main mediator of the proliferation and survival signals provided by G-CSF and IL-6 $[34,35,44,45]$. The hyperphosphorylation displayed by $\operatorname{Shb}$ null cells is thus probably a result of the increased production of G-CSF and IL- 6 .

\section{Conclusions}

The data presented suggest that Shb regulates cues in neoplastic bone marrow of importance for leukemic progression and that absence of Shb decreases disease latency. The Shb-dependent effects include bone marrow cell intrinsic pathways (FAK) as well as niche-dependent signals (cytokine production). Both of these components are considered as druggable targets. Further exploration of the effects of $S h b$ deletion in hematopoietic malignancies is therefore of importance to increase our understanding of mechanisms that control leukemogenesis.

\section{Methods}

Mice

The generation of Shb knockout mice has been described previously [46]. The $S h b$ knockout genotype is not viable on the $\mathrm{C} 57 \mathrm{Bl} / 6$ background and the animals were therefore maintained on the Balb/c strain. The local animal ethics committee at Uppsala University approved all experiments.

\section{Bone marrow transduction and transplantation assay}

The pMIG- $p 210 b c r / a b l$ vector was used to produce retroviruses directing the expression of $B C R-A B L-G F P$ as described previously [47]. Balb/c Shb wild type or knockout mice 8-10 weeks old were treated with 5 -fluorouracil (5FU) (Sigma-Aldrich, St. Lois, MO) at a dose of $150 \mathrm{mg} / \mathrm{kg}$ body weight 6 days prior to bone marrow isolation, in order to enrich for HSCs. Isolated donor bone marrow was stimulated in RPMI 1640 (Sigma Aldrich) supplemented with 10\% FCS (Sigma Aldrich), $2 \mathrm{mM}$ L-glutamine, streptomycin $(0.1 \mathrm{mg} / \mathrm{ml})$, penicillin $(100 \mathrm{U} / \mathrm{ml})$ (All from Gibco, Paisley, UK), IL-3 (10 ng/ml), stem cell factor (SCF) $(10 \mathrm{ng} / \mathrm{ml})$ and IL-6 $(10 \mathrm{ng} / \mathrm{ml})$ (all cytokines were purchased from PeproTech, Rocky Hill, NJ) for 24 hours. The cells were subsequently subjected to two rounds of spin infections over the following 48 hours as described previously [48]. Briefly, $8 \times 10^{6}$ cells were centrifuged for 90 minutes at $1000 \mathrm{~g}$ and $30^{\circ} \mathrm{C}$ in medium containing the aforementioned supplements as well as $25 \%$ viral supernatant, $7.5 \mathrm{mM}$ Hepes (Gibco) and $8 \mu \mathrm{g} / \mathrm{ml}$ Polybrene (Millipore, Watford, UK). Infection efficiency was determined following the second spin inoculation and just prior to transplantation by flow cytometric analysis of green fluorescent protein (GFP) expression on a FACSCalibur (BD Bioscience, Erembodegem, Belgium) and no differences were found between wild type and Shb knockout bone marrow (5.6 $\pm 1.0 \%$ in wt; $4.9 \pm 1.1 \%$ in knockout). Recipient wild type or Shb knockout mice were irradiated with two doses of 4.5 Gy separated by at least 2 hours in a Nordion Gammacell 40 Exacto ${ }^{137} \mathrm{Cs}$ irradiator (MDS Nordion, Ottawa, ON). Immediately following the second irradiation the recipients were retroorbitally injected with a dose of $0.4-1 \times 10^{6}$ cells (equal number of wild type and Shb knockout cells was given per recipient mouse in each experiment, i.e. transfection/transplantation event).

\section{Pathological examination of diseased mice}

The mice were monitored daily from day 6 post -transplantation for signs of disease such as a weight loss of more than $15 \%$ of initial body weight, lethargy and splenomegaly. Moribund mice were then sacrificed. Blood was collected immediately prior to sacrifice and samples were prepared for blood smears. Spleens, livers, and lungs were fixed in $4 \%$ buffered formalin and embedded in paraffin for later histopathological analysis. Iliac bones, femurs and tibias were dissected and bone marrow was collected. Bone marrow cells were extracted from the bones and used for further downstream applications. Single cell suspensions of spleen and bone marrow were also fixed in $4 \%$ paraformaldehyde to enable FACS analysis at a later time point.

\section{Histology}

Fixed and paraffin embedded organs were sectioned in $5 \mu \mathrm{m}$ sections, mounted on microscope slides (Menzel Gläser, Braunschweig, Germany) and stained with Hematoxylin -Eosin. For differential blood counts, peripheral blood smears were stained with May -Grünwald Giemsa.

\section{Fluorescent activated cell-sorting (FACS) analysis}

Paraformaldehyde fixed peripheral blood and bone marrow single cell suspensions were stained with antibodies directed against Gr -1-PE (eBioscience, Hartfield, UK) and rat anti mouse Mac-1 (Invitrogen, Carlsbad, CA) followed by incubation with goat anti-rat PE-Cy5.5 (Invitrogen) secondary antibody.

In order to identify the HSC population, bone marrow and spleen cells were stained with a lineage excluding cocktail consisting of rat anti-mouse antibodies CD3, CD8, CD4, B220, CD19, Gr-1, and Mac-1. The samples were 
thereafter incubated with goat anti-rat PE-Cy5.5, followed by staining with CD150-PE-Cy7 (BioLegend, San Diego, CA), c-Kit-APC eFluor 780, and CD48-PE (eBioscience).

Proliferative and apoptotic rates were determined by analysis of Ki-67 and cleaved Caspase-3. Paraformaldehyde fixed bone marrow was stained for lineage defining markers and c-Kit as described above. This was followed by permeabilization with BD Cytoperm Buffer (BD Bioscience) and incubation with either Ki-67-PE antibody (BD Bioscience) or cleaved Caspase-3 antibody (Cell Signaling Technology, Beverly, MA). Cleaved Caspase-3 activity was detected by a PE-conjugated donkey antirabbit antibody (eBioscience).

All flow cytometric experiments were analyzed with a LSR II (BD Bioscience) and the data was analyzed with FlowJo (TreeStar, Ashland, OR).

\section{Colony forming assays}

Freshly isolated bone marrow and spleen cells were plated on methylcellulose medium M3434 (Stem Cell Technologies, Vancouver, BC) at seeding densities of $2 \times 10^{4}$ and $1 \times$ $10^{5}$ cells, respectively. Bone marrow cells were also seeded onto M3231 supplemented with a gradient of GM-CSF (PeproTech) at concentrations of $0,0.1$ and $1 \mathrm{ng} / \mathrm{ml}$ or $10 \mu \mathrm{M}$ FAK inhibitor 14 (Tocris Bioscience, Bristol, UK). Colonies were scored at day 10.

\section{RNA isolation and real-time reverse transcription PCR}

In order to enrich bone marrow for hematopoietic stem and progenitor cells, c-Kit ${ }^{+}$cells were isolated by magnetic separation with anti-c-Kit labeled magnetic microbeads (Miltenyi Biotec, Bergisch Gladbach, Germany), following the instructions provided by the manufacturer. The number of c-Kit ${ }^{+}$cells was determined and RNA was subsequently isolated using a RNAeasy mini kit (Qiagen, Solna, Sweden). Analysis of gene expression was performed with one- step real-time reverse transcription PCR using QuantiTect $^{\text {tm }}$ SYBR $^{\circ}$ Green RT-PCR kit (Qiagen). The following PCR conditions were used; reverse transcription at $50^{\circ} \mathrm{C}$ for 20 minutes, inactivation at $95^{\circ} \mathrm{C}$ for 15 minutes, $50 \mathrm{cy}$ cles of denaturation at $94^{\circ} \mathrm{C}$ for $15 \mathrm{~s}$, annealing for $25 \mathrm{~s}$ at $60^{\circ} \mathrm{C}$, and extension at $72^{\circ} \mathrm{C}$ for $15 \mathrm{~s}$. All primer sequences can be provided upon request. The PCR reactions were all run a LightCycler ${ }^{\text {ma }}$ real- time PCR machine (Roche Diagnostics, Basel, Switzerland). The Cycle threshold $\left(C_{T}\right)$ values were estimated with the LightCycler Software v 4.1 and transcript levels were normalized by subtracting the corresponding $\beta$-actin values. Control was set at one differences and presented as $2^{-\Delta \mathrm{KOCt}-\mathrm{WTCt}}$.

\section{Immunoblotting}

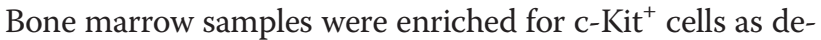
scribed above. Promptly after isolation cells were allowed to rest for 1 hour at $37^{\circ} \mathrm{C}$ in RPMI 1640 medium supplemented with $10 \%$ serum. The cells were subsequently lyzed in SDS sample buffer $(250 \mathrm{mM}$ Tris- $\mathrm{HCl}$ $\mathrm{pH}$ 6.8, 4\% SDS, 10\% glycerol, 0.006\% bromophenol blue, $2 \% \beta$-mercaptoethanol). Samples were then separated by SDS-PAGE and transferred to a Hybond-P membrane (GE Healthcare, Uppsala, Sweden). Blocking of the membranes were done over night at $4^{\circ} \mathrm{C}$ in $5 \% \mathrm{BSA}$, followed by probing for phospho-STAT3, STAT3, FAK (all from Cell Signaling Technology), and phospho-FAK (Invitrogen).

\section{Statistical analysis}

All values are presented as mean \pm SEM. Comparisons of two groups were analyzed by an unpaired Student $t$-test as all data sets were found to be normally distributed. For comparisons between multiple groups one-way ANOVA was used, followed by post hoc analysis with Bonferroni's test. Statistical significance was set to $\mathrm{p}<0.05$.

\section{Additional files}

Additional file 1: Figure S1. A) Hematoxylin-eosin stained sections of lung, liver and spleen of diseased mice transplanted with $B C R-A B L$ transformed bone marrow cells of wild type or Shb knockout background to wild type recipients. B) Percentage myeloid GFP + and GFP- cells in spleen. Means \pm SEM are given and *indicates $p<0.05$.

Additional file 2: Figure S2. Absolute numbers of $B C R-A B L^{+} G F P^{+}$and $B C R-A B L^{-} G^{-}$myeloid cells in peripheral blood. GFP ${ }^{+}$GR-1 ${ }^{\text {Hi }} \mathrm{Mac}-1^{\mathrm{Hi}}$ and GFP $^{-}$GR-1 ${ }^{\mathrm{Hi}}$ Mac- ${ }^{\mathrm{Hi}}$ cells were identified with FACS analysis in order to estimate the number of $B C R-A B L$ carrying cells. Means are presented in arbitrary units \pm SEM and are based on 6 mice of each genotype in 2 independent experiments. *denotes $p<0.05$ as determined by Student's t-test.

Additional file 3: Figure S3. Estimation of HSC proportions in murine $B C R-A B L$ transformed bone marrow. The proportions of HSCs were established using FACS based on expression of lineage defining markers, c-Kit, CD48 and CD150 (a). Right panels are Shb knockout. (b) Percentage CD150+/CD48- cells among c-Kit+/Lin- cells and fraction of GFP + cells among the CD150+/CD48- cells. Means \pm SEM for 6 experiments are shown. (c) Percentage lineage-/c-Kit + or lineage+/c-Kit + cells in bone marrows of wild type or Shb knockout BCR-ABL transformed bone marrow cells transplanted to wild type recipients. Means \pm SEM for 6 mice of each genotype are given.

Additional file 4: Figure S4. Evaluation of cytokine expression in c-Kit enriched and unfractionated (total) bone marrow. (a) Transcript levels of SCF, IL-3, thrombopoietin (Thpo) and angiopoietin-2 (Angpt2) were evaluated with semi-quantitative real-time RT-PCR using mRNA isolated from c-Kit + leukemic bone marrow samples. The expression of proinflammatory cytokines TNFa, IL-1a, IL-1 $\beta, \mathrm{IL}-4, \mathrm{MIP}-1 \mathrm{a}$ and MIP-1 $\beta$ were determined in $\mathrm{c}-\mathrm{Kit}^{+}(\mathrm{b})$ and total bone marrow (d). Expression of G-CSF, IL-6, SCF, IL-3, Angpt-2 and GM-CSF were determined in total bone marrow (c). All $C_{t}$ values were normalized to $\beta$-actin and $S h b$ knockout samples were related to corresponding wild type values. Means are presented as $2_{t}^{-\Delta C} \pm$ SEM to demonstrate fold change in mRNA content. Data are based on 6 mice of each genotype from 2 independent experiments for $\mathrm{c}-\mathrm{Kit}^{+}$cells and 3 mice of each genotype from 1 experiment for unfractionated bone marrow.

Additional file 5: Figure S5. STAT5 activity in $\mathrm{C}-K i t^{+}$bone marrow from leukemic mice. The activation of STAT5 was determined by Western blot analysis of tyrosine phosphorylation by immunoblotting for phospho- and total STAT5 respectively. Protein phosphorylation was related to total protein content on the same blot and signal strength was estimated by densitometric analysis. Means are presented in arbitrary units \pm SEM and are based on 6 mice of each genotype in 2 independent experiments. 


\section{Abbreviations}

FAK: Focal adhesion kinase; Shb: Src homology-2 domain protein B; IL: Interleukin; G-CSF: Granulocyte colony-stimulation factor; STAT: Signaltransducer and activator of transcription; FACS: Fluorescence-activated cell sorting; CML: Chronic myeloid leukemia; HSC: Hematopoietic stem cell; HPC: Hematopoietic progenitor cell; BM: Bone marrow; TNF: Tumor necrosis factor; SCF: Stem cell factor; MIP: Macrophage inflammatory protein CXCL: Chemokine (C-X-C motif) ligand; GFP: Green fluorescent protein; BCR: Breakpoint cluster region.

\section{Competing interests}

The authors declare that they have no competing interests.

\section{Authors' contributions}

$K G, M K$ and $M W$ conceived the experimental design. KG, MJ, CT and MW performed the experiments and analyzed the data. KG, MK and MW interpreted the data. KG and MW wrote the paper. All authors agree on its content.

\section{Acknowledgements}

The work was supported by grants from the Swedish Cancer Foundation 120831, the Swedish Research Council 54X-10822, The Swedish Diabetes Fund DIA-2012-15 and the Family Ernfors Fund. MK was supported by NIH/ NIDDK K01DK084261-01, Sidney Kimmel foundation Foundation for Cancer Research GC2201617 and V Foundation for Cancer Research GC221323.

\section{Author details}

'Department of Medical Cell Biology, Uppsala University, Husargatan 3, 75123 Uppsala, Sweden. ${ }^{2}$ Molecular Pharmacology and Chemistry Program and Center for Cellular Engineering, Memorial Sloan Kettering Institute, 1275 York Ave, 10065 New York, NY, USA.

Received: 24 May 2014 Accepted: 19 June 2014

Published: 21 June 2014

\section{References}

1. Renneville A, Roumier C, Biggio V, Nibourel O, Boissel N, Fenaux P, Preudhomme C: Cooperating gene mutations in acute myeloid leukemia: a review of the literature. Leukemia 2008, 22:915-931.

2. Majeti R, Becker MW, Tian Q, Lee TL, Yan X, Liu R, Chiang JH, Hood L, Clarke MF, Weissman IL: Dysregulated gene expression networks in human acute myelogenous leukemia stem cells. Proc Natl Acad Sci U S A 2009 106:3396-3401.

3. Cancer Genome Atlas Research N: Genomic and epigenomic landscapes of adult de novo acute myeloid leukemia. N Engl J Med 2013, 368:2059-2074.

4. Shtivelman E, Lifshitz B, Gale RP, Canaani E: Fused transcript of abl and bcr genes in chronic myelogenous leukaemia. Nature 1985, 315:550-554.

5. Thomas EK, Cancelas JA, Chae HD, Cox AD, Keller PJ, Perrotti D, Neviani P Druker BJ, Setchell KD, Zheng Y, Harris CE, Williams DA: Rac guanosine triphosphatases represent integrating molecular therapeutic targets for BCR-ABL-induced myeloproliferative disease. Cancer Cell 2007, 12:467-478.

6. Pendergast AM, Quilliam LA, Cripe LD, Bassing CH, Dai Z, Li N, Batzer A, Rabun KM, Der CJ, Schlessinger J, Gishizky ML: BCR-ABL-induced oncogenesis is mediated by direct interaction with the $\mathrm{SH} 2$ domain of the GRB-2 adaptor protein. Cell 1993, 75:175-185.

7. Sattler M, Mohi MG, Pride YB, Quinnan LR, Malouf NA, Podar K, Gesbert F, Iwasaki H, Li S, Van Etten RA, Gu H, Griffin JD, Neel BG: Critical role for Gab2 in transformation by BCR/ABL. Cancer Cell 2002, 1:479-492.

8. Skorski T, Kanakaraj P, Nieborowska-Skorska M, Ratajczak MZ, Wen SC, Zon G, Gewirtz AM, Perussia B, Calabretta B: Phosphatidylinositol-3 kinase activity is regulated by $B C R / A B L$ and is required for the growth of Philadelphia chromosome-positive cells. Blood 1995, 86:726-736.

9. McGahon A, Bissonnette R, Schmitt M, Cotter KM, Green DR, Cotter TG: BCR$\mathrm{ABL}$ maintains resistance of chronic myelogenous leukemia cells to apoptotic cell death. Blood 1994, 83:1179-1187.

10. Zhang B, Ho YW, Huang Q, Maeda T, Lin A, Lee SU, Hair A, Holyoake TL, Huettner C, Bhatia R: Altered microenvironmental regulation of leukemic and normal stem cells in chronic myelogenous leukemia. Cancer Cell 2012, 21:577-592.

11. Reynaud D, Pietras E, Barry-Holson K, Mir A, Binnewies M, Jeanne M, Sala-Torra O, Radich JP, Passegue E: IL-6 controls leukemic multipotent progenitor cell fate and contributes to chronic myelogenous leukemia development. Cancer Cell 2011, 20:661-673.

12. Hoover RR, Gerlach MJ, Koh EY, Daley GQ: Cooperative and redundant effects of STAT5 and Ras signaling in BCR/ABL transformed hematopoietic cells. Oncogene 2001, 20:5826-5835.

13. Pedroza-Gonzalez A, Xu K, Wu TC, Aspord C, Tindle S, Marches F, Gallegos M, Burton EC, Savino D, Hori T, Tanaka Y, Zurawski S, Zurawski G, Bover L, Liu YJ, Banchereau J, Palucka AK: Thymic stromal lymphopoietin fosters human breast tumor growth by promoting type 2 inflammation. J Exp Med 2011, 208:479-490.

14. Wang W, Li Q, Yamada T, Matsumoto K, Matsumoto I, Oda M, Watanabe G, Kayano $Y$, Nishioka $Y$, Sone S, Yano S: Crosstalk to stromal fibroblasts induces resistance of lung cancer to epidermal growth factor receptor tyrosine kinase inhibitors. Clin Cancer Res 2009, 15:6630-6638.

15. Basu S, Hodgson G, Katz M, Dunn AR: Evaluation of role of G-CSF in the production, survival, and release of neutrophils from bone marrow into circulation. Blood 2002, 100:854-861.

16. Kopf M, Baumann H, Freer G, Freudenberg M, Lamers M, Kishimoto T, Zinkernagel R, Bluethmann $H$, Kohler G: Impaired immune and acute-phase responses in interleukin-6-deficient mice. Nature 1994, 368:339-342.

17. Semerad CL, Liu F, Gregory AD, Stumpf K, Link DC: G-CSF is an essential regulator of neutrophil trafficking from the bone marrow to the blood. Immunity 2002, 17:413-423.

18. Schepers K, Pietras EM, Reynaud D, Flach J, Binnewies M, Garg T, Wagers AJ, Hsiao EC, Passegue E: Myeloproliferative neoplasia remodels the endosteal bone marrow niche into a self-reinforcing leukemic niche. Cell Stem Cell 2013, 13:285-299.

19. Frisch BJ, Ashton JM, Xing L, Becker MW, Jordan CT, Calvi LM: Functional inhibition of osteoblastic cells in an in vivo mouse model of myeloid leukemia. Blood 2012, 119:540-550.

20. Cujec TP, Medeiros PF, Hammond P, Rise C, Kreider BL: Selection of v-abl tyrosine kinase substrate sequences from randomized peptide and cellular proteomic libraries using mRNA display. Chem Bio/ 2002, 9:253-264

21. Lindholm CK, Frantz JD, Shoelson SE, Welsh M: Shf, a Shb-like adapter protein, is involved in PDGF-alpha-receptor regulation of apoptosis. Biochem Biophys Res Commun 2000, 278:537-543.

22. Oda T, Kujovich J, Reis M, Newman B, Druker BJ: Identification and characterization of two novel $\mathrm{SH} 2$ domain-containing proteins from a yeast two hybrid screen with the ABL tyrosine kinase. Oncogene 1997, 15:1255-1262.

23. Welsh M, Mares J, Karlsson T, Lavergne C, Breant B, Claesson-Welsh L: Shb is a ubiquitously expressed Src homology 2 protein. Oncogene 1994, 9:19-27.

24. Anneren C, Lindholm CK, Kriz V, Welsh M: The FRK/RAK-SHB signaling cascade: a versatile signal-transduction pathway that regulates cell survival, differentiation and proliferation. Curr Mol Med 2003, 3:313-324.

25. Hagerkvist R, Mokhtari D, Lindholm C, Farnebo F, Mostoslavsky G, Mulligan RC, Welsh N, Welsh M: Consequences of Shb and c-Abl interactions for cell death in response to various stress stimuli. Exp Cell Res 2007, 313:284-291.

26. Kriz V, Agren N, Lindholm CK, Lenell S, Saldeen J, Mares J, Welsh M: The SHB adapter protein is required for normal maturation of mesoderm during in vitro differentiation of embryonic stem cells. J Biol Chem 2006, 281:34484-34491.

27. Gustafsson K, Calounova G, Hjelm F, Kriz V, Heyman B, Gronvik KO, Mostoslavsky G, Welsh M: Shb deficient mice display an augmented TH2 response in peripheral CD4+ T cells. BMC Immunol 2011, 12:3.

28. Gustafsson K, Heffner G, Wenzel PL, Curran M, Grawe J, McKinney-Freeman SL, Daley GQ, Welsh M: The Src homology 2 protein Shb promotes cell cycle progression in murine hematopoietic stem cells by regulation of focal adhesion kinase activity. Exp Cell Res 2013, 319:1852-1864.

29. Hestdal K, Ruscetti FW, Ihle JN, Jacobsen SE, Dubois CM, Kopp WC, Longo DL, Keller JR: Characterization and regulation of RB6-8C5 antigen expression on murine bone marrow cells. J Immunol 1991, 147:22-28.

30. Daley GQ, Van Etten RA, Baltimore D: Induction of chronic myelogenous leukemia in mice by the P210bcr/abl gene of the Philadelphia chromosome. Science 1990, 247:824-830.

31. Hariharan IK, Adams JM, Cory S: bcr-abl oncogene renders myeloid cell line factor independent: potential autocrine mechanism in chronic myeloid leukemia. Oncogene Res 1988, 3:387-399.

32. Klein H, Becher R, Lubbert M, Oster W, Schleiermacher E, Brach MA, Souza L, Lindemann A, Mertelsmann RH, Herrmann F: Synthesis of granulocyte 
colony-stimulating factor and its requirement for terminal divisions in chronic myelogenous leukemia. J Exp Med 1990, 171:1785-1790.

33. Irish JM, Hovland R, Krutzik PO, Perez OD, Bruserud O, Gjertsen BT, Nolan GP: Single cell profiling of potentiated phospho-protein networks in cancer cells. Cell 2004, 118:217-228.

34. Tian SS, Lamb P, Seidel HM, Stein RB, Rosen J: Rapid activation of the STAT3 transcription factor by granulocyte colony-stimulating factor. Blood 1994, 84:1760-1764.

35. Lutticken C, Wegenka UM, Yuan J, Buschmann J, Schindler C, Ziemiecki A, Harpur AG, Wilks AF, Yasukawa K, Taga T, Kishimoto T, Barbieri G, Pellegrini S, Sendtner M, Heinrich PC, Horn F: Association of transcription factor APRF and protein kinase Jak1 with the interleukin-6 signal transducer gp130. Science 1994, 263:89-92.

36. Tyner JW, Walters DK, Willis SG, Luttropp M, Oost J, Loriaux M, Erickson H, Corbin AS, O'Hare T, Heinrich MC, Deininger MW, Druker BJ: RNAi screening of the tyrosine kinome identifies therapeutic targets in acute myeloid leukemia. Blood 2008, 111:2238-2245.

37. Gotoh A, Miyazawa K, Ohyashiki K, Tauchi T, Boswell HS, Broxmeyer HE, Toyama K: Tyrosine phosphorylation and activation of focal adhesion kinase (p125FAK) by BCR-ABL oncoprotein. Exp Hematol 1995, 23:1153-1159.

38. Recher C, Ysebaert L, Beyne-Rauzy O, Mansat-De Mas V, Ruidavets JB, Cariven P, Demur C, Payrastre B, Laurent G, Racaud-Sultan C: Expression of focal adhesion kinase in acute myeloid leukemia is associated with enhanced blast migration, increased cellularity, and poor prognosis. Cancer Res 2004 64:3191-3197.

39. Le Y, Xu L, Lu J, Fang J, Nardi V, Chai L, Silberstein LE: FAK silencing inhibits leukemogenesis in BCR/ABL-transformed hematopoietic cells. Am J Hematol 2009, 84:273-278.

40. Despeaux M, Labat E, Gadelorge M, Prade N, Bertrand J, Demur C, Recher C, Bonnevialle P, Payrastre B, Bourin P, Racaud-Sultan C: Critical features of FAKexpressing $A M L$ bone marrow microenvironment through leukemia stem cell hijacking of mesenchymal stromal cells. Leukemia 2011, 25:1789-1793.

41. Maeda K, Baba Y, Nagai Y, Miyazaki K, Malykhin A, Nakamura K, Kincade PW, Sakaguchi N, Coggeshall KM: IL-6 blocks a discrete early step in lymphopoiesis. Blood 2005, 106:879-885.

42. Maeda K, Malykhin A, Teague-Weber BN, Sun XH, Farris AD, Coggeshall KM: Interleukin-6 aborts lymphopoiesis and elevates production of myeloid cells in systemic lupus erythematosus-prone B6.Sle1.Yaa animals. Blood 2009, 113:4534-4540.

43. Maxson JE, Gotlib J, Pollyea DA, Fleischman AG, Agarwal A, Eide CA, Bottomly D, Wilmot B, McWeeney SK, Tognon CE, Pond JB, Collins RH, Goueli B, Oh ST, Deininger MW, Chang BH, Loriaux MM, Druker BJ, Tyner JW: Oncogenic CSF3R mutations in chronic neutrophilic leukemia and atypical CML. N Engl J Med 2013, 368:1781-1790.

44. Panopoulos AD, Zhang L, Snow JW, Jones DM, Smith AM, El Kasmi KC, Liu F, Goldsmith MA, Link DC, Murray PJ, Watowich SS: STAT3 governs distinct pathways in emergency granulopoiesis and mature neutrophils. Blood 2006, 108:3682-3690.

45. Minami M, Inoue M, Wei S, Takeda K, Matsumoto M, Kishimoto T, Akira S: STAT3 activation is a critical step in gp130-mediated terminal differentiation and growth arrest of a myeloid cell line. Proc Natl Acad Sci U S A 1996, 93:3963-3966.

46. Kriz V, Mares J, Wentzel P, Funa NS, Calounova G, Zhang XQ, Forsberg-Nilsson K, Forsberg M, Welsh M: Shb null allele is inherited with a transmission ratio distortion and causes reduced viability in utero. Dev Dyn 2007, 236:2485-2492.

47. Pear WS, Miller JP, Xu L, Pui JC, Soffer B, Quackenbush RC, Pendergast AM, Bronson R, Aster JC, Scott ML, Baltimore D: Efficient and rapid induction of a chronic myelogenous leukemia-like myeloproliferative disease in mice receiving P210 bcr/abl-transduced bone marrow. Blood 1998, 92:3780-3792.

48. Li S, llaria RL Jr, Million RP, Daley GQ, Van Etten RA: The P190, P210, and P230 forms of the BCR/ABL oncogene induce a similar chronic myeloid leukemia-like syndrome in mice but have different lymphoid leukemogenic activity. J Exp Med 1999, 189:1399-1412.

doi:10.1186/1756-8722-7-45

Cite this article as: Gustafsson et al:: The Src homology-2 protein Shb modulates focal adhesion kinase signaling in a $B C R-A B L$ myeloproliferative disorder causing accelerated progression of disease. Journal of Hematology \& Oncology 2014 7:45

\section{Submit your next manuscript to BioMed Central and take full advantage of:}

- Convenient online submission

- Thorough peer review

- No space constraints or color figure charges

- Immediate publication on acceptance

- Inclusion in PubMed, CAS, Scopus and Google Scholar

- Research which is freely available for redistribution 